\title{
NR4A1 Promotes Diabetic Nephropathy by Activating Mff-Mediated Mitochondrial Fission and Suppressing Parkin-Mediated Mitophagy
}

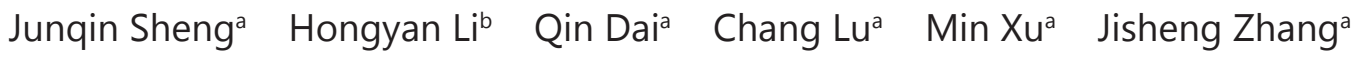 \\ Jianxun Feng ${ }^{a}$ \\ aDepartment of Nephrology, Xuhui District Central Hospital of Shanghai, Shanghai, bepartment of \\ Nephrology, Huadu District People's Hospital, Southern Medical University, Guangzhou, China
}

\section{Key Words}

Mff • NR4A1 • Parkin • Mitochondrial fission • Mitophagy • Diabetic renal damage

\begin{abstract}
Background/Aims: Disrupted mitochondrial dynamics, including excessive mitochondrial fission and mitophagy arrest, has been identified as a pathogenic factor in diabetic nephropathy (DN), although the upstream regulatory signal for mitochondrial fission activation and mitophagy arrest in the setting of DN remains unknown. Methods: Wild-type (WT) mice and NR4A1 knockout (NR4A1-KO) mice were used to establish a DN model. Mitochondrial fission and mitophagy were evaluated by western blotting and immunofluorescence. Mitochondrial function was assessed by JC-1 staining, the MPTP opening assay, immunofluorescence and western blotting. Renal histopathology and morphometric analyses were conducted via $\mathrm{H} \& \mathrm{E}$, Masson and PASM staining. Kidney function was evaluated via ELISA, western blotting and qPCR. Results: In the present study, we found that nuclear receptor subfamily 4 group A member 1 (NR4A1) was actually activated by a chronic hyperglycemic stimulus. Higher NR4A1 expression was associated with glucose metabolism disorder, renal dysfunction, kidney hypertrophy, renal fibrosis, and glomerular apoptosis. At the molecular level, increased NR4A1 expression activated p53, and the latter selectively stimulated mitochondrial fission and inhibited mitophagy by modulating Mff and Parkin transcription. Excessive Mff-related mitochondrial fission caused mitochondrial oxidative stress, promoted mPTP opening, exacerbated proapoptotic protein leakage into the cytoplasm, and finally initiated mitochondria-dependent cellular apoptosis in the setting of diabetes. In addition, defective Parkin-mediated mitophagy repressed cellular ATP production and failed to correct the uncontrolled mitochondrial fission. However, NR4A1 knockdown interrupted the Mff-related mitochondrial fission and recused Parkin-mediated mitophagy, reducing the hyperglycemia-mediated mitochondrial damage and thus improving
\end{abstract}

Junqin Sheng and Hongyan Li contributed equally to this work. 


\section{Cellular Physiology Cell Physiol Biochem 2018;48:1675-1693 \\ \begin{tabular}{l|l|l} 
and Biochemistry Published online: August 2, 2018 & $\begin{array}{l}\text { (c) } 2018 \text { The Author(s). Published by S. Karger AG, Basel } \\
\text { www.karger.com/cpb }\end{array}$
\end{tabular} \\ Sheng et al:: NR4A1 Regulates Diabetic Nephropathy}

renal function. Conclusion: Overall, we have shown that NR4A1 functions as a novel malefactor in diabetic renal damage and operates by synchronously enhancing Mff-related mitochondrial fission and repressing Parkin-mediated mitophagy. Thus, finding strategies to regulate the balance of the NR4A1-p53 signaling pathway and mitochondrial homeostasis may be a therapeutic option for treating diabetic nephropathy in clinical practice.

(C) 2018 The Author(s)

Published by S. Karger AG, Basel

\section{Introduction}

Diabetic nephropathy (DN), the renal damage caused by hyperglycemia, is a common complication of diabetes, affecting as many as of $50 \%$ of patients [1]. Notably, DN has gradually become a leading cause of chronic kidney disease worldwide and has been identified as one of the most significant long-term complications for diabetes patients in terms of morbidity and mortality [2]. Chronic hyperglycemia has also been acknowledged to play a decisive role in the development of DN[3]. At the molecular level, several of the biological processes affected by high glucose, including glomerular apoptosis, interstitial fibrosis, and metabolic reprogramming $[4,5]$, are tightly linked to mitochondrial homeostasis, and each of these processes is strongly affected by alterations in the balance of mitochondrial dynamics [6, 7], including mitochondrial fission and mitophagy [8]. These facts indicate that changes in mitochondrial morphology may underlie many of the phenotypes that control the pathological progression of DN.

In certain physiological conditions, mitochondria undergo morphologic changes to adapt to cellular energy demands. Mitochondria divide into daughter mitochondria by mitochondrial fission, increasing energy production [9]. However, under conditions of hyperglycemia, mitochondria become small, roundish fragments due to excessive fission, contributing to the progression of DN[10]. Previous findings indicate that hyperglycemiamediated mitochondrial fission induces ROS overproduction, obligating cells to undergo oxidative stress. In addition, uncontrolled mitochondrial division produces a large amount of mitochondrial debris, leading to an inadequate distribution of mitochondrial DNA within the mitochondria [11]. The damage to the mitochondrial genome suppresses the copying and transcription of the mitochondrial respiratory complex, interrupting cellular ATP production [12]. Abnormal mitochondrial fission promotes the opening of the mitochondrial permeability transition pore (mPTP) and cytochrome-c (cyt-c) leakage from mitochondria into cytoplasm, finally activating mitochondria-dependent cellular apoptosis $[13,14]$. These findings highlight the fact that mitochondrial fission is regulated by glucose metabolism and, in turn, governs the development of diabetes and DN. Notably, although there is considerable evidence that mitochondrial fission is a potential target for retarding or preventing diabetic renal damage, the initial upstream molecular mechanism of hyperglycemia-mediated mitochondrial fission remains poorly understood.

Structurally, mitochondrial fission is tightly controlled by dynamin-related protein 1 (Drp1) and its receptor. In response to a hyperglycemic stimulus, Drp1 is activated by Rhoassociated protein kinase 1 (ROCK1) pathways and translocates from the cytoplasm to the surface of mitochondria $[15,16]$, forming a ring structure around the mitochondria. Notably, Drp1's interaction with mitochondria requires its receptor, and mitochondrial fission factor (Mff) is an indispensable adaptor protein for Drp1. Previous research has suggested that Mff activation is required for mitochondrial fission and cardiac endothelial oxidative injury $[11,17]$. However, the upstream regulatory molecule for Mff-required mitochondrial fission in the setting of DN remains unknown. In response to mitochondrial fission, mitochondria could employ lysosomes via Parkin to degrade damaged mitochondria and maintain a healthy mitochondrial population, which is essential for cell survival [18-20]. Notably, the impairment of Parkin-mediated mitophagy is a feature of DN, and various pharmacological activators of mitophagy have been shown to protect against glomerulosclerosis and proteinuria, renal hypertrophy, and mesangial expansion in rodent DN models [21-23]. However, the regulatory signaling upstream of mitophagy is far from clear. Give these 
facts, we designed our study to explore the mechanism by which hyperglycemia controls mitochondrial fission and mitophagy.

Previous studies of fatty liver disease [24] have suggested that mitochondrial fission and mitophagy could be synchronously modulated by nuclear receptor subfamily 4 group A member 1 (NR4A1), a subfamily of NR4A orphan receptors. The NR4A1 activation induced by a high-fat diet promotes Drp1 phosphorylation and Bnip3 transcriptional arrest, selectively stimulating Drp1-mediated mitochondrial fission and inhibiting Bnip3-related mitophagy [24]. In addition, upregulated NR4A1 also induces high-fat associated endothelial dysfunction and atherosclerosis formation by regulating Parkin-mediated mitophagy activity [25]. On this basis, we aimed to investigate whether NR4A1 is upregulated by hyperglycemia and activates Mff-required mitochondrial fission and represses Parkin-related mitophagy, finally leading to mitochondrial dysfunction, glomerular mitochondrial apoptosis, and the development of DN.

\section{Materials and Methods}

\section{Ethical statement}

Experimental protocol was approved by the Xuhui District Central Hospital of Shanghai. All animal studies were carried out according to the guidelines of Animal Care and Use Committee. All efforts were made to minimize the suffering of the experimental rats in this research.

\section{Animal study and cellular experiments}

Wild-type (WT) and NR4A1 knockout (NR4A1-KO) mice with a C57BL/6 background were purchased from Jackson Laboratory (Bar Harbor, ME, USA) and were bred at the laboratory of Xuhui District Central Hospital of Shanghai. Then, 8-week-old wild-type (WT) and NR4A1-KO mice were intraperitoneally injected with streptozotocin (STZ, $50 \mathrm{mg} / \mathrm{kg}$ ) for 5 consecutive days based on the results of our previous study [26]. The diabetic model was validated by blood glucose levels $>16 \mathrm{mmol} / \mathrm{L}$ after a six-hour daytime fasting and at the end of treatment, all mice (24-week-old) were euthanized, and the kidneys were collected for further experimentations. All mice were maintained on a 12-h/12-h light/dark cycle with free access to tap water and laboratory chow [10].

Human renal mesangial cells (HRMCs) were purchased from the Cell Bank of the Chinese Academy of Sciences (Shanghai, China). To mimic the high glucose damage, normal glucose medium (5.5 mmol/L) and high glucose medium (25 mmol/L) were used for approximately $12 \mathrm{~h}$ according to the values in a previous study [27]. In the current study, to activate mitochondrial fission, FCCP (5 $\mu \mathrm{M})$ was used to pretreat cells for approximately $30 \mathrm{~min}$. To inhibit mitochondrial fission, mitochondrial division inhibitor 1 (Mdivi-1; $10 \mathrm{mM}$; Sigma-Aldrich; Merck KGaA) was used for 2 h [28].

\section{Histological studies}

Four percent buffered formalin-fixed kidney tissues were embedded in paraffin based on a previous study. Tissue sections with $5 \mu \mathrm{m}$ thickness were prepared and stained with hematoxylin-eosin (HE) stain, Masson trichrome stain and periodic Schiff-methenamine (PASM) stain as described in our previous study [15]. The changes in tissue morphology were observed through a light microscope and captured by the attached camera.

\section{Biochemical parameter measurement}

Blood pressures were measured in conscious, acclimatized mice using the tail-cuff method. After 12 $\mathrm{h}$ of fasting, the blood glucose level of venous blood from the tail vein was measured using a glucometer (Roche, Mannheim, Germany). Blood and urine samples were collected. Glycated hemoglobin (HbA1c) was measured using the in2it A1C system (Bio-Rad, Hercules, CA). The triglyceride and cholesterol levels in the serum and kidney and the TBARS levels in the kidney were determined using commercial assay kits (Nanjing Jiancheng Company, Shanghai, China)[29]. To collect morning spot urine samples, animals were placed in metabolic cages at the beginning of the light cycle and were kept for $2 \mathrm{~h}$ with water but without food. To obtain the 24-h urine samples, animals were placed in metabolic cages at the beginning of the light 


\section{Cellular Physiology Cell Physiol Biochem 2018;48:1675-1693 and Biochemistry \begin{tabular}{c|c} 
DOI: 10.1159/000492292 \\
Published online: August 2, 2018 & $\begin{array}{l}\text { O 2018 The Author(s). Published by S. Karger AG, Basel } \\
\text { www.karger.com/cpb }\end{array}$
\end{tabular} \\ Sheng et al.: NR4A1 Regulates Diabetic Nephropathy}

cycle and were kept for $24 \mathrm{~h}$ with free access to water and a standard laboratory diet [30]. The levels of creatinine and blood urea nitrogen (BUN) were determined using a Cobas ${ }^{\circledR}$ C311 Autoanalyzer as per the manufacturer's protocols. The urinary albumin concentration was determined using an ELISA kit obtained from BioMedical Assays (Beijing, China)[31]. The levels of insulin, glucagon, C-reactive protein, C-peptide, TNF $\alpha$, MCP-1, and IL-6 were determined using ELISA kits obtained from Cusabio Technology (Wuhan, China). The lipid hydroperoxides (LPOs) in kidney homogenates were determined using an LPO kidney assay kit (Cayman Chemical, Ann Arbor, MI)[32].

\section{Estimation of oxidative stress biomarkers in kidney tissue}

The reduced glutathione (GSH) content of kidney tissue homogenates was estimated as described in our previous study [26]. Briefly, 10\% kidney tissue homogenates in EDTA were centrifuged at $4^{\circ} \mathrm{C}$ after mixing with ice cold $10 \%$ trichloroacetic acid (TCA). Then, the supernatants were mixed with Tris-HCl buffer ( $\mathrm{pH}$ 9.0) followed by DTNB for color development, and the absorbance of that colored solution was measured at $412 \mathrm{~nm}$ by a spectrophotometer [33]. The values were expressed in nmoles of GSH/mg of protein. Oxidized glutathione (GSSG) was used as a substrate, and the oxidation of NAPDH to NADP was monitored at $340 \mathrm{~nm}$. The specific activity of the enzyme was expressed as $\mathrm{U} / \mathrm{mg}$ of protein as described in our previous study [34].

\section{Preparation of cytosolic and mitochondrial fractions}

Kidney tissues were homogenized in ice cold $50 \mathrm{mM}$ phosphate buffer containing $0.1 \mathrm{mM}$ EDTA, pH 7.4. The homogenate (10\%) was subjected to centrifugation at $2000 \mathrm{rpm}$ for 10 minutes at $4^{0} \mathrm{C}$ to remove nuclear portion as pellet [35]. Then supernatant was collected and again centrifuged at $15000 \mathrm{rpm}$ for 40 minutes $\left(4^{\circ} \mathrm{C}\right)$. Supernatant was considered as cytosolic sample and after collection of supernatant, the pellet was re-suspended in sucrose buffer to obtain mitochondrial sample. Both the samples were stored at $-20^{\circ} \mathrm{C}$ for biochemical assays [36].

\section{Western blot analysis}

Cytosolic and mitochondrial fractions were used for western blot assay. Fifty micro gram of protein was loaded for immunodetection. Samples were resolved by 10\% SDS-PAGE. Electroblotting apparatus was used to transfer the proteins to PVDF membrane by operating the apparatus at $85 \mathrm{~V}$ for 60 min using transfer buffer [37]. After transfer, the membrane was blocked by 5\% non fat dried milk in Tris buffered saline and then incubated with the respective antibody for overnight at $4^{\circ} \mathrm{C}$. Next day, after washing the membrane thrice with TBST; it was kept into secondary antibody for 2-hour. Next, the membrane was washed with TBST at least thrice [38]. Then, immunoblots were developed in presence of alkaline phosphatase buffer containing NBT and BCIP and relative abundance of the bands were quantified using Image J software (NIH, Bethesda, MD, USA). The primary antibodies used in the present study were as follows: Bcl2 (1:1000, Cell Signaling Technology, \#3498), Bax (1:1000, Cell Signaling Technology, \#2772), caspase9 (1:1000, Cell Signaling Technology, \#9504), pro-caspase3 (1:1000, Abcam, \#ab13847), cleaved caspase3 (1:1000, Abcam, \#ab49822), c-IAP (1:1000, Cell Signaling Technology, \#4952), cyt-c (1:1, 000; Abcam; \#ab90529), Drp1 (1:1000, Abcam, \#ab56788), ), Opa1 (1:1000, Abcam, \#ab42364), Mfn1 (1:1000, Abcam, \#ab57602), Mff (1:1000, Cell Signaling Technology, \#86668), LC3II (1:1000, Cell Signaling Technology, \#3868), Tim23 (1:1000, Santa Cruz Biotechnology, \#sc-13298), p62 (1:1000, Cell Signaling Technology, \#5114), Parkin (1:1000, Cell Signaling Technology, Inc.), Tom20 (1:1, 000, Abcam, \#ab186735), NR4A1 (1:1000, Cell Signaling Technology, \#3960), total-p53 (1:1000, Cell Signaling Technology, \#9282), phospho-p53 (Ser15) (1:1000, Cell Signaling Technology, \#9284)[39]. Band intensities were normalized to the respective internal standard signal intensity (GAPDH (1:1000, Cell Signaling Technology, \#5174) and/ or $\beta$-actin (1:1000, Cell Signaling Technology, \#4970) using Quantity One Software (version 4.6.2; Bio-Rad Laboratories, Inc.).

\section{TUNEL assay}

The terminal deoxynucleotidyl transferase UTP nick end-labeling (TUNEL) assay was performed with frozen tumor tissue sections at seven days after exposure, using the In Situ Cell Death Detection Kit (Roche Diagnostics, Branford, CT, USA) according to the manufacturer's instructions [40]. After washing 3 times for 


\section{Cellular Physiology Cell Physiol Biochem 2018;48:1675-1693 \begin{tabular}{l|l|l} 
and Biochemistry Published 10.1159/000492292 & $\begin{array}{l}\text { (c) } 2018 \text { The Author(s). Published by S. Karger AG, Basel } \\
\text { www.karger.com/cpb }\end{array}$
\end{tabular} \\ Sheng et al:: NR4A1 Regulates Diabetic Nephropathy}

5 min each in PBS, the sections were mounted in fluorescence mounting medium with DAPI (Invitrogen) to identify the nuclei. All the paired sections were examined under a confocal laser scanning microscopy [41].

\section{Immunofluorescence confocal microscopy}

The cells were washed twice with PBS, permeabilized in $0.1 \%$ Triton X-100 overnight at $4^{\circ} \mathrm{C}$. After the fixation procedure, the sections were cryoprotected in a PBS solution supplemented with $0.9 \mathrm{~mol} / \mathrm{l}$ of sucrose overnight at $4^{\circ} \mathrm{C}[42]$. After neutralization with $\mathrm{NH}_{4} \mathrm{Cl}$ buffer, the sections were permeabilized for $45 \mathrm{~min}$ with $0.05 \%$ saponin/PBS $(\mathrm{pH}=7.4)$ and incubated overnight with the following primary antibodies: cyt-c (1:500; Abcam; \#ab90529), DAPI (Sigma- Aldrich, St. Louis, MO, USA), lysosome stain (Beyotime, Beijing, China), and a mitochondrion-selective MitoFluor ${ }^{\mathrm{TM}}$ stain (Molecular Probes, Burlington, ON, Canada) were used to label the nuclei, lysosomes, and mitochondria, respectively. Confocal immunofluorescence images were taken using the FV10-ASW 1.7 software and the Olympus IX81 microscope. Mitophagy is the result of fusion between mitochondria and lysosome. The green mitochondria locate with red lysosome would generate the orange mitophagy [43]. Then, the number of orange dot was measured to quantify the number of mitophagy. The length of mitochondria was measured under microscope which was used to quantify the mitochondrial fission.

\section{MTT assay and caspase-3/9 activity detection}

The MTT assay was performed to measure the cell viability as described in a previous study [13]. Cells were treated with $50 \mu \mathrm{l}$ of MTT at $37^{\circ} \mathrm{C}$ for $\sim 4 \mathrm{~h}$. Subsequently, the cells were incubated with 200 $\mu$ of dimethyl sulfoxide for $\sim 10 \mathrm{~min}$ at $37^{\circ} \mathrm{C}$. The optical density at a wavelength of $570 \mathrm{~nm}$ was then determined [44]. To analyze changes in caspase-3/9, caspase-3/9 activity kits (Beyotime Institute of Biotechnology, China; Catalog No. C1158) were used according to the manufacturer's protocols [45]. To analyze the caspase-3 activity, $5 \mu \mathrm{l}$ of DEVD-p-NA substrate ( $4 \mathrm{mM}, 200 \mu \mathrm{M}$ final concentration) was added to the samples for $2 \mathrm{~h}$ at $37^{\circ} \mathrm{C}$. In brief, to measure caspase- 9 activity, $5 \mathrm{ml}$ of LEHD-p-NA substrate ( $4 \mathrm{mM}, 200 \mu \mathrm{M}$ final concentration) was added to the samples for $1 \mathrm{~h}$ at $37^{\circ} \mathrm{C}$. Then, the absorbance at a wavelength at $400 \mathrm{~nm}$ was recorded via a microplate reader as a marker of the caspase- 3 and caspase- 9 activities [46].

Measurement of mitochondrial permeability transition pore (MPTP), reactive oxygen species (ROS) and the mitochondrial membrane potential $(\Delta \Psi \mathrm{m})$

A JC-1 assay was used to investigate the mitochondrial potential. Briefly, cells $\left(1 \times 10^{6}\right)$ were treated with a MitoProbe ${ }^{\mathrm{TM}} \mathrm{JC}-1$ assay kit (Thermo Fisher Scientific Inc.) $(10 \mathrm{mg} / \mathrm{ml})$ at $37^{\circ} \mathrm{C}$ in the dark for $15-20$ min [47]. Subsequently, PBS was used to wash the cells three times. Finally, the mitochondrial potential was determined using a fluorescence microscope, and images were captured. Red-orange fluorescence was attributable to potential-dependent aggregation in the mitochondria. Green fluorescence, indicating the monomeric form of JC-1, appeared in the cytosol after mitochondrial membrane depolarization [48]. In the mPTP opening assay, calcein-acetoxymethyl ester (5 $\mu$ M, cat. no. 148504-34-1; Sigma-Aldrich; Merck KGaA) was incubated with cells at room temperature in the dark for $30 \mathrm{~min}$. Subsequently, the mPTP opening rate was determined as described in a previous study [49]. Techniques to measure ROS were performed as previously described. Briefly, cells were incubated with the ROS-sensitive dye DHE and then incubated for $20 \mathrm{~min}$ at $37^{\circ} \mathrm{C}[50]$.

\section{RNA interference}

The siRNAs against NR4A, Parkin and p53 were obtained from RiboBio (Guangzhou, China). Transfection was carried out via incubating cells with siRNAs in Opti-MEM media supplemented with Lipofectamine ${ }^{\circledR} 2000$ (Invitrogen; Thermo Fisher Scientific, Inc.) according to the manufacturer's protocol [51]. Infection was performed for $48 \mathrm{~h}$ at $37^{\circ} \mathrm{C}$ and infection efficiency was confirmed via western blotting.

\section{Statistical analysis}

Data are presented as means \pm S.E. One way analysis of variances (ANOVA) followed by post hoc test (Tukey's HSD test) was employed to search for possible significant changes in between the mean values of different treatment groups. Each experiment was repeated at least for 3 times and statistical analysis was performed using Microcal Origin version 7.0. 


\section{Results}

NR4A1 is activated by hyperglycemia and promotes the development of diabetes

To determine whether NR4A1 is involved in the development of diabetic kidney damage, western blotting was used to measure NR4A1 expression. As shown in Fig. $1 \mathrm{~A}-\mathrm{B}$, compared to the control group, the group with chronic hyperglycemia had higher NR4A1 transcription and expression, which indicates NR4A1 activation by hyperglycemia. To determine whether the augmented NR4A1 was sufficient to cause diabetic kidneys, NR4A1 knockout (NR4A1-KO) mice were used. Then, we analyzed the general characteristics of diabetic mice and NR4A1-KO mice. As expected, compared to the weight in the control group, the body weight was significantly increased in the diabetic mice and reduced by genetic ablation of NR4A1 (Fig. $1 \mathrm{C}$ ). In addition, the blood glucose (Fig. 1 D), C-peptide (Fig. 1 E), HbA1c (Fig. $1 \mathrm{~F}$ ), glucagon (Fig. $1 \mathrm{G}$ ), systolic blood pressure (Fig. $1 \mathrm{H}$ ), and serum insulin (Fig. 1 I) levels in diabetic mice were markedly higher than those in the control group. However, the genetic ablation of NR4A1 reversed the above parameters. Moreover, the inflammatory factors were also increased in response to hyperglycemia and were restored to near-normal levels following NR4A1 deletion (Fig. $1 \mathrm{~J}-\mathrm{L}$ ). In summary, these results support the functional importance of NR4A1 activation in promoting the development of diabetes.

\section{Genetic ablation of NR4A1 attenuates diabetic renal injury}

To more specifically measure the ability of activated NR4A1 to exacerbate diabetic kidney injury, we evaluated renal function. The blood urea nitrogen (BUN) (Fig. 2 A) and serum creatinine levels (Fig. 2 B) were mostly elevated in diabetic mice but reduced by NR4A1 deletion. Similarly, the urinary albumin content (Fig. 2 C) and the albumin-creatinine ratio (ACR) (Fig. 2 D) were also upregulated in response to a hyperglycemic stimulus but downregulated in response to NR4A1 deletion.

To evaluate renal hypertrophy, we weighed the kidneys. The absolute kidney weights were greatly increased in diabetic mice but decreased after NR4A1 deficiency (Fig. 2 E). These results were supported by histological evaluation via H\&E and PASM staining. 
Compared with the control group, the diabetic mice exhibited moderate glomerular atrophy and fragmentation, epithelial desquamation, renal tubule degeneration (Fig. 2 F-I), and kidney glomerular basement membrane thickening (Fig. 2 J-J). By contrast, the hyperglycemia-induced renal histopathological alterations were partly attenuated by NR4A1 deletion.

Cellular oxidative stress is a well-established factor in promoting diabetic renal injury. Interestingly, the hyperglycemia-elevated lipid hydroperoxides (LPO) (Fig. 2 $\mathrm{J}-\mathrm{K}$ ) and urinary 8-isoprostane levels (Fig. 2 L) were obviously reduced in the NR4A1-KO mice. Furthermore, compared with the control group, the diabetic mice contained less glutathione (GSH) (Fig. $2 \mathrm{M}$ ) and more GSSG (the oxidized form of GSH) (Fig. $2 \mathrm{~N}$ ), and this phenotypic change was reduced by NR4A1 deletion. Based on these data, it is apparent that the pathogenesis of diabetic renal damage is associated with NR4A1 activation.

\section{NR4A1 inhibition suppresses} hyperglycemia-mediated glomerular apoptosis and kidney fibrosis

The hallmarks of diabetic renal damage include glomerular cell apoptosis and renal interstitial fibrosis. Compared with the control group, chronic hyperglycemia upregulated the expression of proapoptotic factors and downregulated the content of antiapoptotic proteins (Fig. 3 A-G); this effect was mostly reversed by NR4A1 deletion. In addition, the caspase- 3 activity (Fig. $3 \mathrm{H}$ ) was notably increased by a hyperglycemic stimulus and decreased by NR4A1 deletion. These data indicate that NR4A1 activation by hyperglycemia is an endogenous danger signal for glomerular death.

Renal fibrosis was observed via Masson staining. The results showed that the renal fibrosis area was increased significantly more under chronic high glucose stimulus and was reduced to near-normal levels by NR4A1 deletion (Fig. $3 \mathrm{I}-\mathrm{J}$ ). These changes in the fibrosis area coincided with the significant increase in collagen I/III/IV expression observed via western blotting analysis (Fig. $3 \mathrm{~K}-\mathrm{N}$ ). By contrast, genetic ablation of NR4A1 abolished

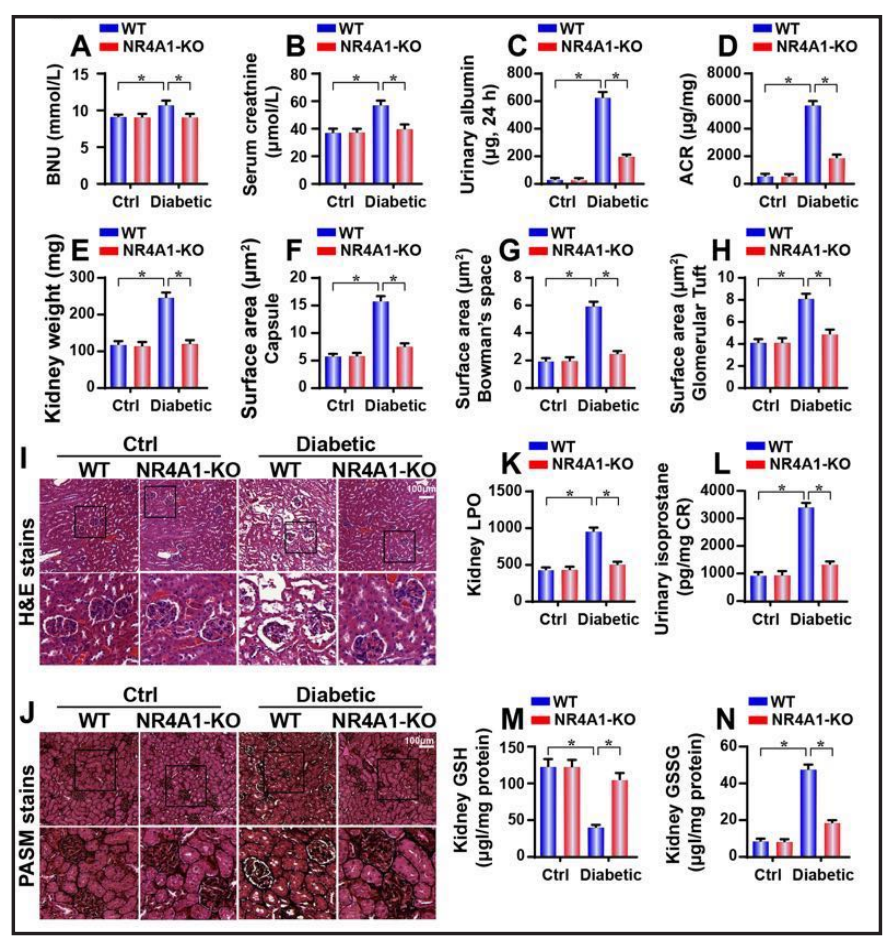

Fig. 2. Genetic ablation of NR4A1 attenuates renal injury in diabetic mice. A-B. The blood urea nitrogen (BUN) and serum creatinine levels were measured via ELISA in WT mice and NR4A1KO mice. C. To obtain the 24-h urine samples, animals were placed in metabolic cages, and the urinary albumin was measured. D. The urinary albumin content and albumin-creatinine ratio (ACR) were also recorded. E. The kidney weight was measured in WT mice and NR4A1-KO mice. F-I. The kidney was obtained, and HE staining was performed to observe the structural alterations in the diabetic kidney upon with NR4A1 deletion. Subsequently, the surface areas in Bowman's capsule, Bowman's space and glomerular
tufts were recorded. J. PASM staining of the kidney. K-L. The lipid hydroperoxides (LPOs) in kidney homogenates were measured using an LPO kidney assay kit. The urinary 8-isoprostane was measured by collecting the urine from WT mice and NR4A1-KO mice. M-N. Kidneys were collected, and the proteins were isolated to analyze the oxidative stress markers via ELISA. Experiments were repeated three times, and data are shown as the mean \pm SEM. $\mathrm{n}=6$ mice per group. ${ }^{*} \mathrm{P}<0.05$. 
Fig. 3. NR4A1 genetic deletion reduces high glucose-induced glomerular apoptosis. A-G. Proteins were isolated from WT mice and NR4A1-KO mice, and then, western blotting was performed to analyze the apoptotic protein expression. $\mathrm{H}$. The kidneys were collected, and then, the tissue caspase-3 activity was measured via ELISA. I-J. Masson staining was carried out to observe the kidney fibrosis. K-P. Proteins were isolated from WT mice and NR4A1-KO mice, and then, western blotting was performed to analyze the fibrosis-related protein expression. Q. The kidneys were collected, and then, the tissue MMP-9 activity was measured via ELISA. Experiments were repeated three times, and data are shown as the mean \pm SEM. $n=6$ mice per group. ${ }^{*} \mathrm{P}<0.05$.

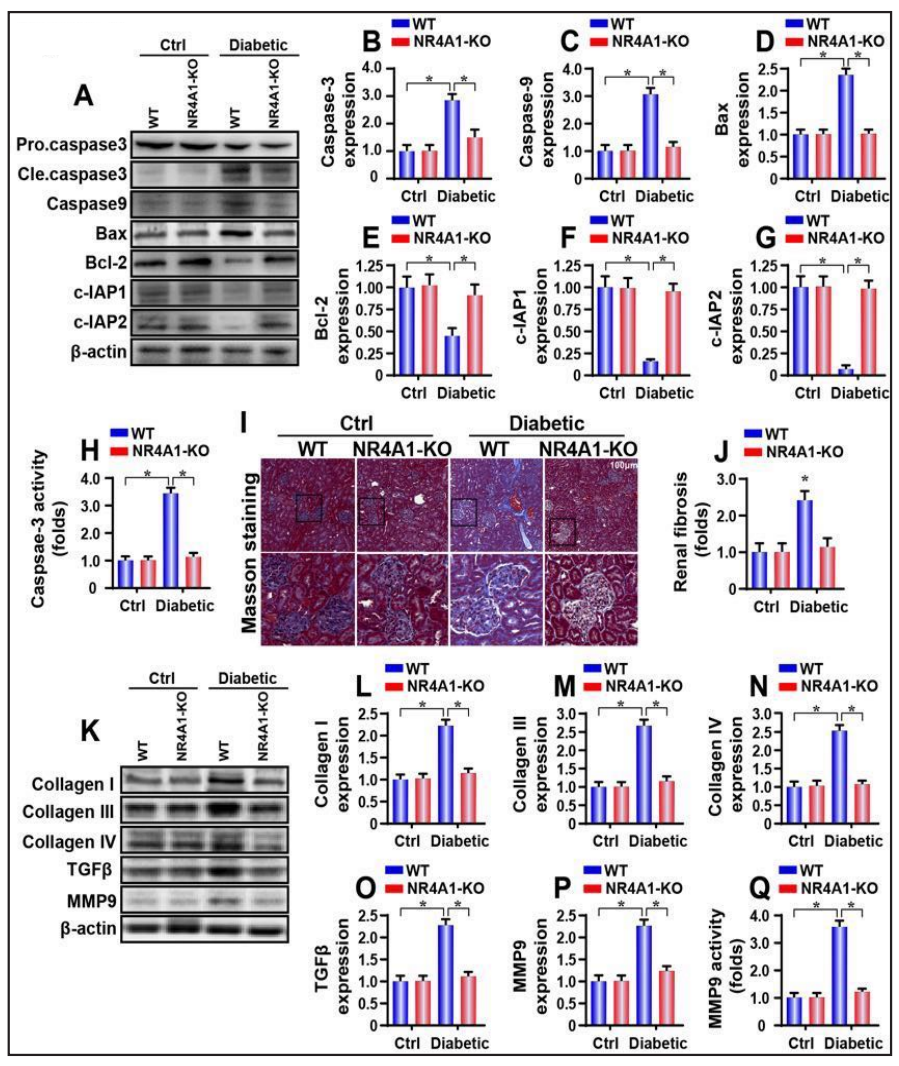

the augmented collagen protein expression induced by hyperglycemia. Furthermore, the activated TGF $\beta$ pathways due to hyperglycemia were greatly repressed by NR4A1 deletion (Fig. 3 K-Q). This change was followed by a decrease in MMP-9 expression and activity (Fig. 3 $\mathrm{K}-\mathrm{Q}$ ). Altogether, these results highlight the key role of NR4A1 activation as a master regulator of diabetic renal damage via promoting glomerular apoptosis and triggering kidney fibrosis.

\section{Loss of NR4A1 represses hyperglycemia-associated mitochondrial dysfunction}

Diabetic renal damage is characterized by mitochondrial dysfunction, a high production of ROS, and low levels of ATP [52]. Our next experiments were carried out to observe whether NR4A1 activation interferes with mitochondrial homeostasis. In vitro, renal mesangial cells were cultured with high glucose medium, and then, the cellular ROS production was measured via an immunofluorescence assay. Compared with the control group, the group with high glucose treatment had increased cellular ROS production (Fig. 4 A-B), and this effect was mostly repressed by NR4A1 knockdown via transfection with NR4A1 siRNA. Excessive ROS generation was accompanied by a decreased mitochondrial membrane potential $(\triangle \Psi \mathrm{m})$ (Fig. 4 C-D) and increased mPTP opening (Fig. 4 E). However, transfection with NR4A1 siRNA maintained the $\triangle \Psi \mathrm{m}$ and suppressed mPTP opening. Excessive mPTP opening promotes the leakage of mitochondrial proapoptotic factors, such as cyt-c, from the mitochondria into the cytoplasm and nucleus. As shown in Fig. 4 F-G, the nuclear expression of cyt-c under hyperglycemic treatment was higher than that in the control group. However, NR4A1 siRNA repressed the hyperglycemia-mediated cyt-c leakage into the nucleus. Upon the release of cyt-c into the cytoplasm, the protein would bind apoptotic protease activating factor (Apaf-1) and thereby activate caspase-9, initiating caspase-dependent apoptotic signals [33]. Western blotting showed that hyperglycemia significantly increased the caspase-9, caspase-3, and Bax expression (Fig. 4 H-M). By contrast, antiapoptotic proteins such as Bcl-2 and c-IAP1 were downregulated in response to a hyperglycemic stimulus (Fig. $4 \mathrm{H}-\mathrm{M})$. Interestingly, the loss of NR4A1 greatly reduced the decrease in antiapoptotic protein 


\section{Cellular Physiology Cell Physiol Biochem 2018;48:1675-1693

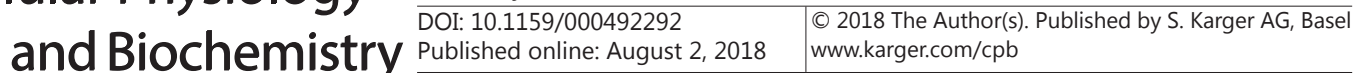

expression and repressed the proapoptotic factor upregulation, suggesting that NR4A1 inhibition provides a survival advantage for glomerular viability by maintaining mitochondrial function in the context of hyperglycemia.

Mff-mediated mitochondrial fission is activated by NR4A1 and contributes to the hyperglycemia-mediated glomerular mitochondrial damage

Previous studies have demonstrated a strong correlation between hyperglycemia-mediated mitochondrial dysfunction and mitochondrial fission [10, 14]. Furthermore, in light of the central role of mitochondrial fission in initiating mitochondrial apoptosis, we asked whether mitochondrial fission is required for NR4A1-mediated glomerular apoptosis and mitochondrial damage. As shown in Fig. 5AB, a hyperglycemic stimulus forced the mitochondria to divide into several fragmented mitochondria. As a result, the average length of mitochondria decreased from $8.7 \pm 1.2 \mu \mathrm{m}$ to $2.7 \pm 0.6 \mu \mathrm{m}$. Interestingly, this conformational alteration was mostly reversed by NR4A1 knockdown. At the molecular level, hyperglycemia contributed to the Drp1 translocation from the cytoplasm to the surface of the mitochondria (Fig. 5 C-D), and this effect was largely repressed by NR4A1 knockdown. We also examined the molecular alterations of mitochondrial fusion, a kind of resistance mechanism for correcting excessive mitochondrial fission. As shown in Fig. 5 C-G, hyperglycemia drastically downregulated and NR4A1 deletion reversed the expression

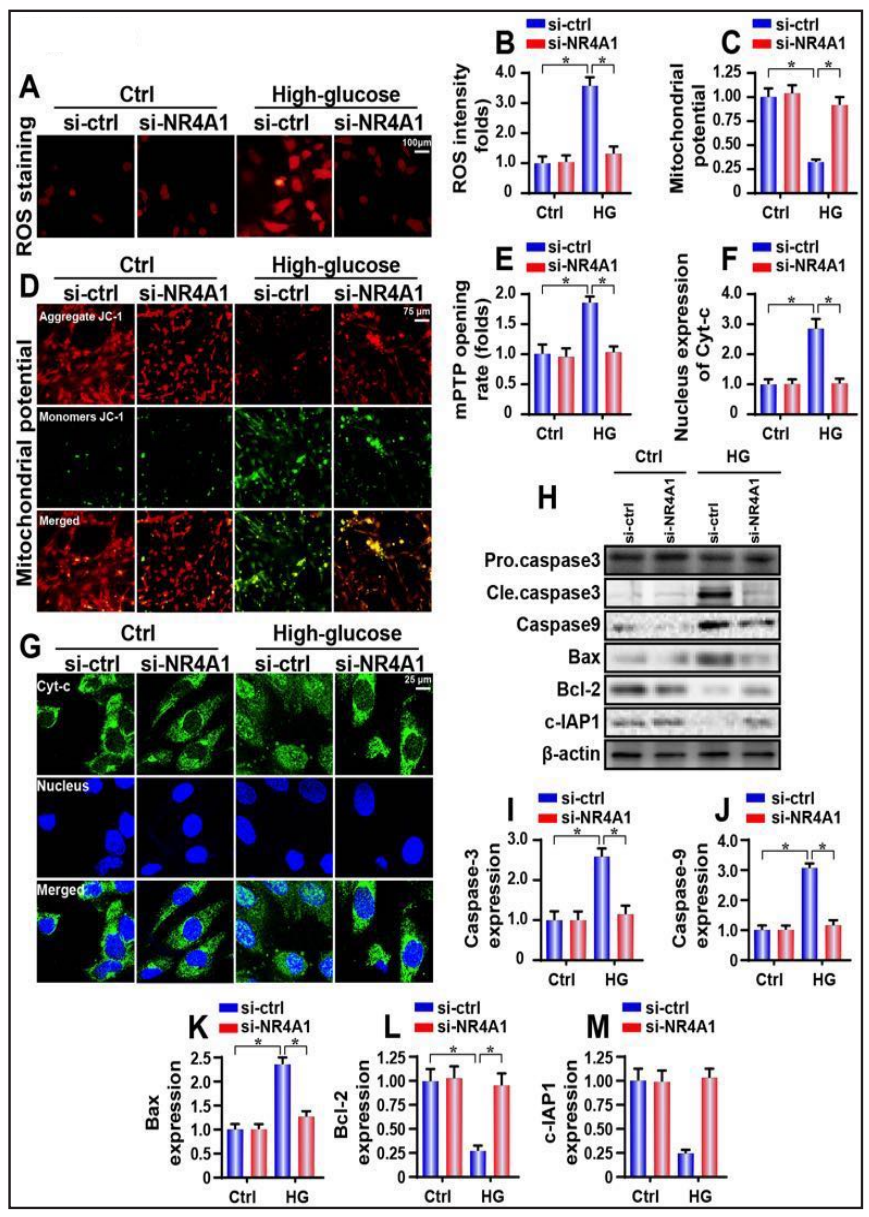

Fig. 4. NR4A1 knockdown represses hyperglycemia-associated mitochondrial dysfunction. A-B. Renal mesangial cells were cultured with normal glucose medium (5.5 mmol/L) and high glucose medium (25 mmol/L) for $12 \mathrm{~h}$. To inhibit the NR4A1 expression, control siRNA (si-ctrl) and NR4A1 siRNA (siNR4A1) were transfected into cells before the high glucose stimulus. Then, ROS staining was performed using a ROS probe. The relative ROS fluorescence intensity was measured. C-D. After high glucose treatment, the mitochondrial membrane potential was measured via JC-1 staining. Red fluorescence indicates a normal mitochondrial potential, whereas green fluorescence indicates an impaired mitochondrial potential. E. mPTP opening was recorded with or without NR4A1 silencing. F-G. Immunofluorescence assay for cyt-c. In response to high glucose treatment, more cyt-c was released into the nucleus, and this effect was inhibited by NR4A1 deletion. H-M. After high glucose treatment, proteins were isolated, and western blotting was performed to analyze the expression of apoptotic proteins. Experiments were repeated three times, and data are shown as the mean \pm SEM. si-ctrl: control siRNA; si-NR4A1: NR4A1 siRNA; HG: high glucose. ${ }^{*} \mathrm{P}<0.05$. 
of mitochondrial fusion-related proteins, such as Mfn1 and Opa1. This finding indicated that hyperglycemia triggered mitochondrial fission in an NR4A1-dependent manner.

Subsequently, to verify that NR4A1-activated mitochondrial fission is involved in hyperglycemia-induced mitochondrial apoptosis, we performed caspase-9 activity and LDH-release assays to evaluate the mitochondrial damage and cellular death, respectively. Additionally, gain- and loss-of-function assays for mitochondrial fission were conducted via the administration of Mdivi-1 (mitochondrial fission blocker) and FCCP (mitochondrial fission activator), respectively. As shown in Fig. $5 \mathrm{H}$, the hyperglycemia-triggered caspase- 9 activation was mostly inhibited by NR4A1 deletion or Mdivi-1 supplementation. However, FCCP treatment abrogated the inhibitory effect of NR4A1 deletion in terms of caspase- 9 activation. Similar results were obtained in the LDH-release assay (Fig. 5 I). These investigations have established a central role for NR4A1 upregulation and for the subsequent mitochondrial fission activation that leads to glomerular mitochondrial apoptosis.

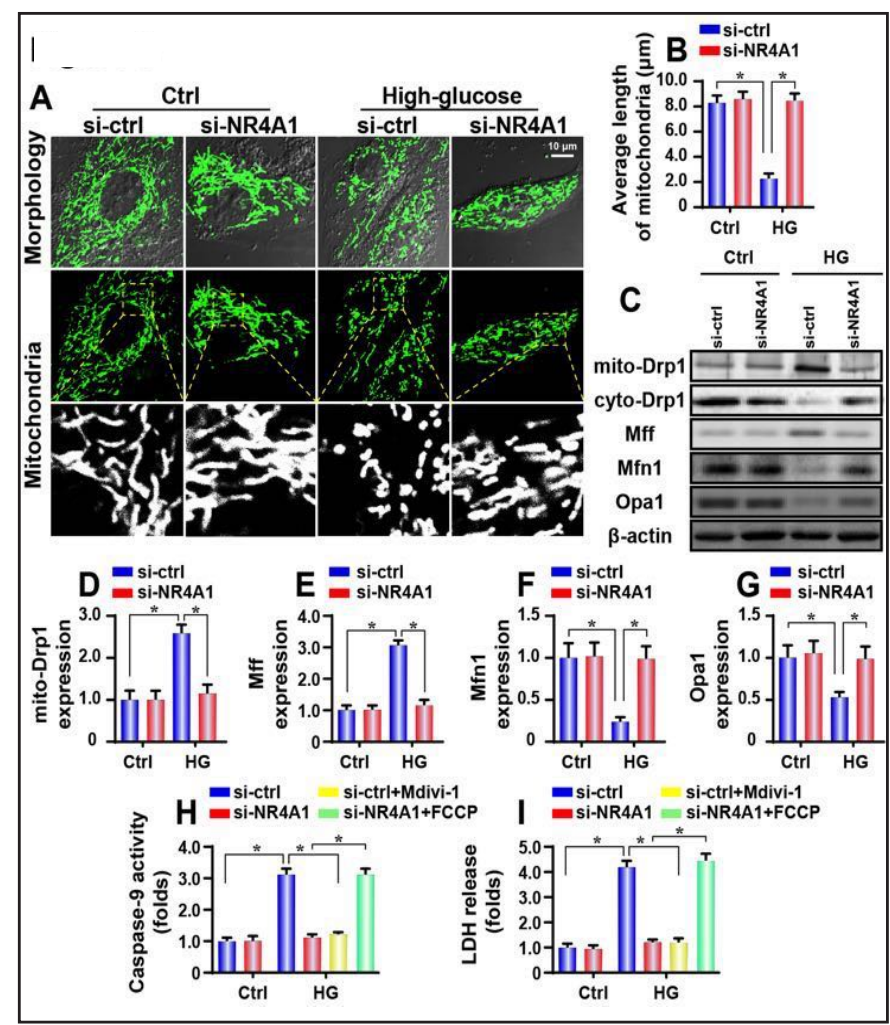

Fig. 5. NR4A1 suppresses high glucose-mediated mitochondrial fission. A-B. After high glucose treatment, mitochondria were observed via an immunofluorescence assay. Then, the average length of mitochondria was recorded. C-G. To quantify mitochondrial fission, proteins were isolated, and western blotting was performed to analyze the expression of proteins related to mitochondrial fission. H-I. To verify the role of mitochondrial fission in cellular apoptosis, loss- and gain-of-function assays were performed to evaluate mitochondrial fission. FCCP, an activator of mitochondrial fission, was added to NR4A1-deleted cells to reactivate mitochondrial fission. Mdivi-1, an inhibitor of mitochondrial fission, was administered to HG-treated cells to suppress mitochondrial fission. Subsequently, the caspase-9 activity and LDH release were measured. Experiments were repeated three times, and the data are shown as the mean \pm SEM. si-ctrl: control siRNA; si-NR4A1: NR4A1 siRNA; HG: high glucose. $* \mathrm{P}<0.05$.

\section{Protective Parkin-mediated}

mitophagy is repressed by NR4A1

In addition to mitochondrial fission, we further investigated the contributory role of NR4A1 in regulating Parkin-mediated mitophagy $[53,54]$. Western blot with the cytoplasmic and mitochondrial fractions showed that hyperglycemia reduced the mitochondrial Parkin expression (Fig. 6 A-B). In response to Parkin downregulation, the LC3II/LC3I ratio was reduced (Fig. 6 A-D), but the p62 accumulation was increased (Fig. 6 A-D), indicating the inhibition of autophagic flux. However, NR4A1 deletion reversed the Parkin expression and sustained the autophagic flux. Subsequently, to observe mitophagy activity, we isolated mitochondria and analyzed LC3II via western blotting. The results showed that mito-LC3II (mitochondrial LC3II) was reduced by hyperglycemia and returned to normal levels after NR4A1 deletion (Fig. 6 A-E). In addition, the expression of Tom 20 (outer membrane marker) 
Fig. 6. NR4A1 regulates Parkinmediated mitophagy. A-G. After high glucose treatment, proteins were isolated, and western blotting was performed to analyze the expression of proteins related to mitophagy. To determine whether Parkin is necessary for mitophagy, siRNA against Parkin was transfected in NR4A1-deleted cells. H-I. To observe mitophagy, an immunofluorescence assay for mitophagy was carried out by costaining mitochondria and lysosomes. Then, the number of mitophagy events was recorded. J. The average length of mitochondria was measured with Parkin knockdown. K. ATP production was measured to establish the functional role of Parkinmediated mitophagy in mitochondrial energy metabolism. L-M. ROS production was measured via flow cytometry with Parkin knockdown. Experiments were repeated three times, and data are shown as the mean \pm SEM. si-ctrl: control siRNA; si-NR4A1: NR4A1 siRNA; si-Parkin: Parkin siRNA; HG: high glucose. $* \mathrm{P}<0.05$.
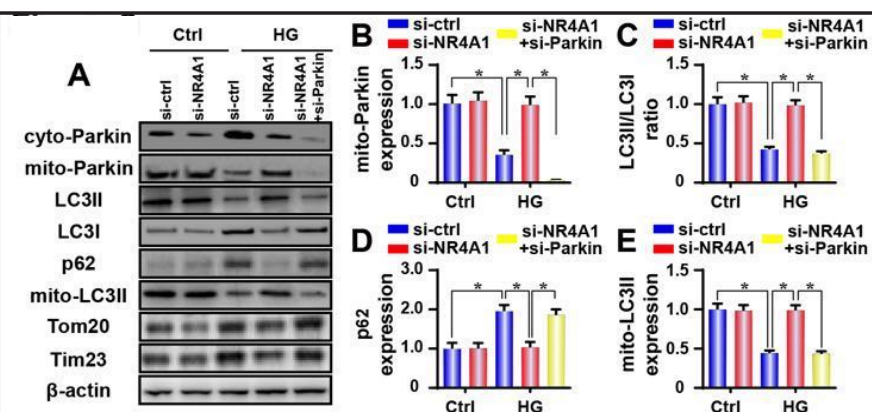

D $=\begin{array}{ll}\text { si-ctrl } \\ \text { si-NR4A1 } & \text { si-NR4A1 } \\ \text { +si-Parkin }\end{array}$
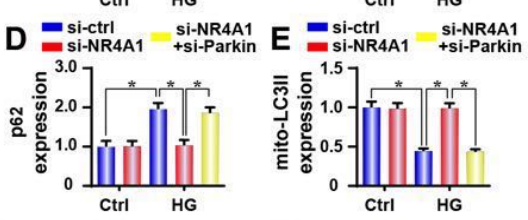

F $=\begin{array}{ll}\text { si-ctrl } & \text { si-NR4A1 } \\ \text { si-NR4A1 } & \text { tsi-Parkin }\end{array}$
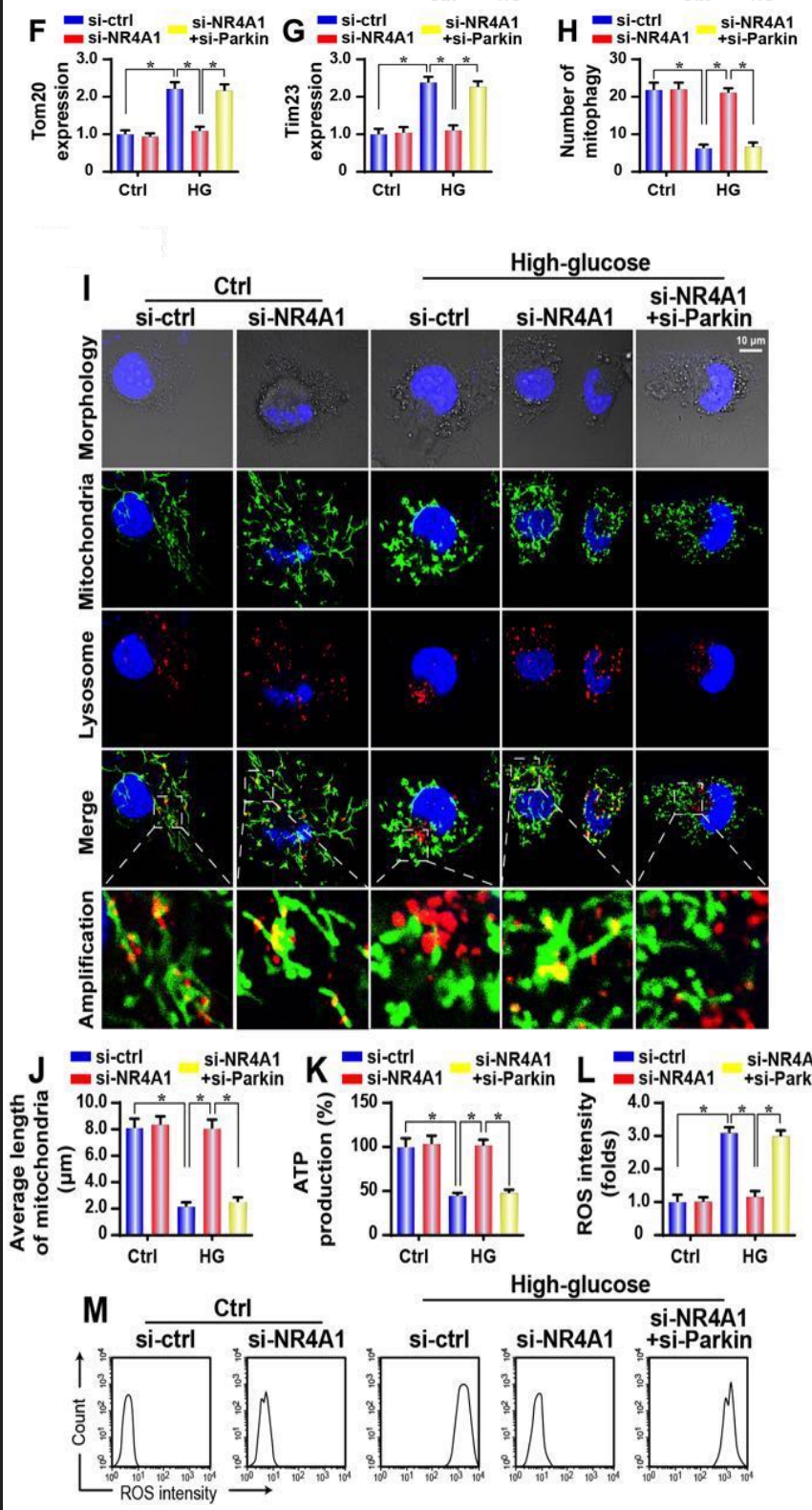

High-glucose

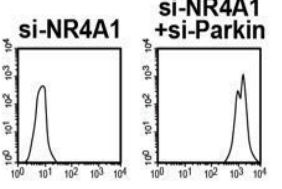

and Tim 23 (inner membrane marker) were decreased in response to hyperglycemia (Fig. 6 A-G), and this effect was also reduced by NR4A1 deficiency. To more specifically evaluate the ability of the Parkin to promote mitophagy, a siRNA against Parkin was used. After knockdown of Parkin in NR4A1-deficient cells, the mito-LC3II expression was reduced, and this change was accompanied by the accumulation of Tom20 and Tim23 (Fig. 6 A-G), suggesting an 
indispensable role of Parkin in mitophagy activation. Taken together, this information indicated that the Parkin-mediated mitophagy was inhibited by hyperglycemia via NR4A1. This finding was further validated via an immunofluorescence assay. As shown in Fig. 6 H-I, hyperglycemia disrupted the cooperation between mitochondria and lysosomes, indicating mitophagy delay. However, the loss of NR4A1 stimulated the colocalization of mitochondria and lysosomes, and this effect was nullified by Parkin siRNA.

To examine the functional role of Parkin-mediated mitophagy in mitochondrial homeostasis, we measured the average mitochondrial length [55]. As shown in Fig. $6 \mathrm{~J}$, the decreased mitochondrial length induced by hyperglycemia was reversed to near-normal levels after NR4A1 deletion. However, the inhibitory effects of NR4A1 deficiency on mitochondrial fission were abolished by Parkin siRNA. These data indicated that Parkin-mediated mitophagy had the ability to correct excessive mitochondrial fission. Subsequently, we measured mitochondrial ATP production with Parkin knockdown. As shown in Fig. $6 \mathrm{~K}$, hyperglycemia was reduced, whereas NR4A1 deficiency increased ATP generation by reversing the change in Parkin expression. In addition to maintaining ATP, knockdown of NR4A1 repressed the cellular ROS production via Parkin-mediated mitophagy (Fig. 6 L-M). Altogether, this information illustrates that Parkin-mediated mitophagy is a kind of defense mechanism to combat hyperglycemia-mediated mitochondrial damage and that this activity is drastically repressed by NR4A1.

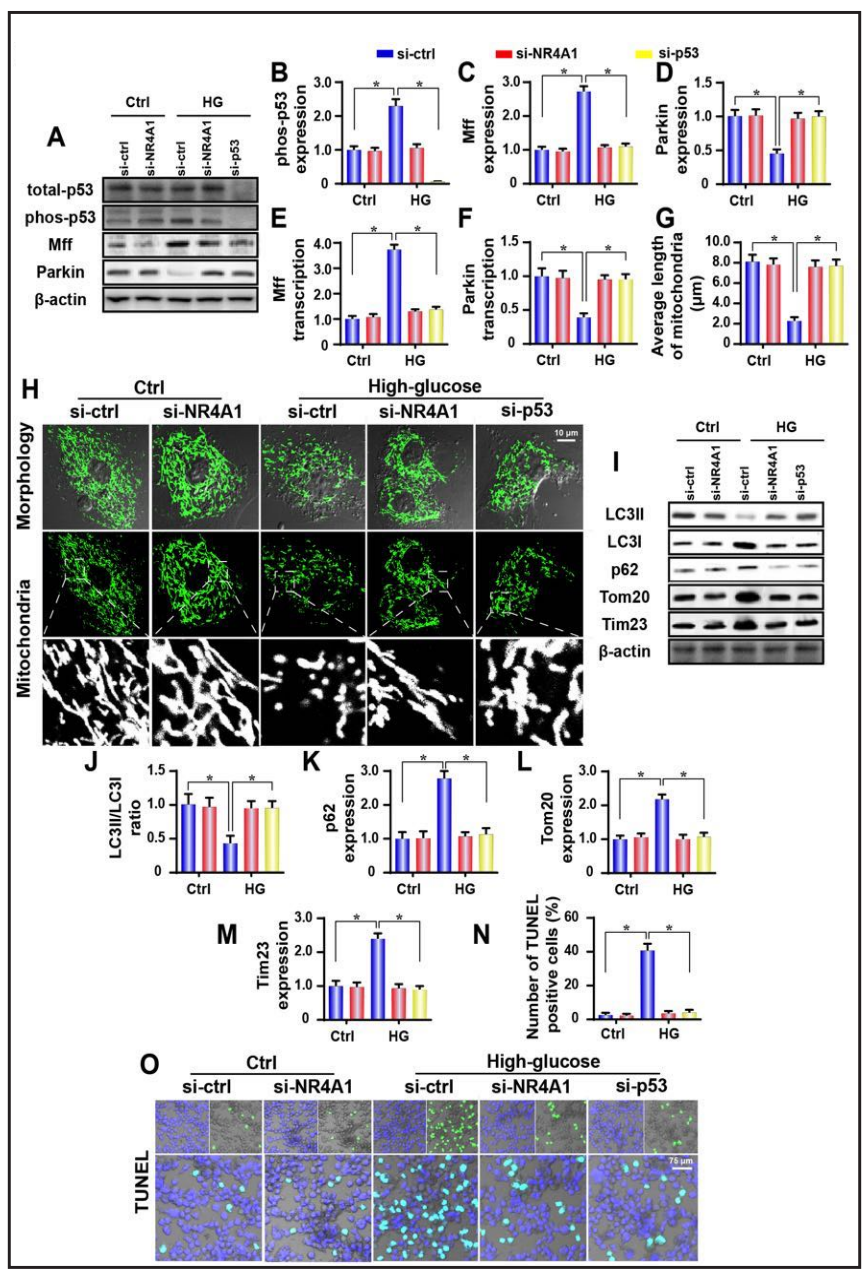

Fig. 7. NR4A1 modulates Mff and Parkin via the p53 signaling pathway. A-F. After high glucose treatment, proteins were isolated, and western blotting was performed. High glucose treatment activated the p53 pathway via promoting its phosphorylation, and this effect was negated by NR4A1 silencing. Moreover, the Mff and Parkin expression levels were inhibited in response to p53 siRNA. G-H. To determine whether p53 is required for NR4A1-related mitochondrial fission, p53 siRNA was transfected into cells, and mitochondria were observed via immunofluorescence. I-M. To determine whether p53 is required for NR4A1-related mitophagy, western blotting was performed to analyze the expression of proteins involved in mitophagy. $\mathrm{N}-\mathrm{O}$. A TUNEL assay was carried out in p53-deleted cells to establish its role in hyperglycemia-related cellular apoptosis. Experiments were repeated three times, and data are shown as the mean \pm SEM. si-ctrl: control siRNA; si-NR4A1: NR4A1 siRNA; si-p53: p53 siRNA; HG: high glucose. ${ }^{*} \mathrm{P}<0.05$. 


\section{Cellular Physiology Cell Physiol Biochem 2018;48:1675-1693 \begin{tabular}{l|l} 
DOI: 10.1159/000492292 & and Biochemistry \\
Published online: August 2, 2018 & $\begin{array}{l}\text { O } 2018 \text { The Author(s). Published by S. Karger AG, Basel } \\
\text { www.karger.com/cpb }\end{array}$
\end{tabular} Sheng et al.: NR4A1 Regulates Diabetic Nephropathy}

\section{NR4A1 regulates Parkin and Mff transcription via p53}

Previous studies have confirmed that p53, as a downstream effector of NR4A1, synchronously governs both mitochondrial fission and mitophagy in fatty liver disease $[24,56]$. In the present study, we also found that p53 was activated by hyperglycemia via posttranscriptional phosphorylation (Fig. 7 A-B) and that this effect was negated by NR4A1 deletion. Subsequently, to determine whether $\mathrm{p} 53$ is required for Mff upregulation and Parkin downregulation, siRNA against p53 was used for a loss-of-function assay of p53. Loss of p53 reduced the Mff expression and increased the Parkin content found in western blot analysis (Fig. 7 A-D). Similar results were also obtained via a qPCR assay (Fig. 7 E-F), suggesting that p53 governs Mff and Parkin expression at the transcriptional level.

Subsequently, we performed experiments to explore whether p53 is required for mitochondrial fission and mitophagy. As shown in Fig. 7 G-H, the increased mitochondrial debris induced by hyperglycemia was strongly inhibited by NR4A1 deletion. This result was similar to the one obtained via p53 siRNA transfection. These data indicated that p53 activation by NR4A1 accounted for mitochondrial fission. We also found that mitophagy parameters were reduced by hyperglycemia and returned to normal levels after NR4A1 deletion (Fig. 7 I-M). Interestingly, loss of p53 also maintained the mitophagy activity, confirming that mitophagy activity is highly regulated by p53 in the context of high glucose stress (Fig. 7 I-M). Finally, the loss of p53 and the inhibition of NR4A1 each reduced the number of TUNEL-positive cells compared to those in high glucose-treated cells (Fig. $7 \mathrm{~N}-\mathrm{O}$ ). Altogether, these data revealed that NR4A1 modulates Mff-mediated mitochondrial fission and Parkin-mediated mitophagy via p53.

\section{Discussion}

Hyperglycemia and diabetic renal damage are directly related to mitochondrial dysfunction through poorly understood mechanisms. The data of the present study have provided us with a novel description of the mechanism underlying hyperglycemia-mediated mitochondrial damage. We found the following: (1) NR4A1 is upregulated in response to a chronic hyperglycemic stimulus and contributes to the development of DN, (2) genetic ablation of NR4A1 improves the abnormal changes in glucose metabolism parameters, sustains renal function, attenuates renal hypertrophy, and reduces diabetic kidney damage, (3) at the molecular level, deletion of NR4A1 suppresses glomerular apoptosis and prevents the mitochondrial damage induced by high glucose stress, and (4) mechanically, the loss of NR4A1 inactivates p53 and alleviates Mff transcription. On the one hand, (5) downregulated Mff disrupts the hyperglycemia-mediated mitochondrial fission and thus reduces mitochondrial oxidative stress, represses mPTP opening, decreases the leakage of proapoptotic proteins into the cytoplasm, and stops the mitochondria-dependent cellular apoptosis in the setting of diabetes; on the other hand, (6) inactive NR4A1-p53 signaling enhances Parkin transcription, augmenting mitophagy activity, and (7) activated mitophagy increases ATP production and represses mitochondrial fission. To the best of our knowledge, this is the first identification of the major mitochondrial homeostasis regulatory pathway involving NR4A1 upregulation, p53 activation, Mff-mediated mitochondrial fission initiation, Parkin-mediated mitophagy inhibition, and glomerular apoptosis amplification in the development of diabetic renal injury (Fig. 8). This finding suggests the possibility that NR4A1/p53 signaling pathways act as new upstream regulators of hyperglycemia-modulated mitochondrial fission and mitophagy, which lays the foundation to help us understand the paradigm of mitochondrial dynamics management and signaling in the context of diabetic nephropathy.

An increasing body of evidence has confirmed the strong causal association between mitochondrial impairment and diabetic nephropathy [26]. A chronic hyperglycemic stimulus increases the production of mitochondrial ROS, establishing glomerular oxidative 
stress $[57,58]$. Redox imbalance initiates cellular damage by modifying phospholipids and proteins in the mitochondrial membrane $[6,59]$. According to previous studies, hyperglycemiamediated oxidative stress reduces the expression and activity of the mitochondrial respiratory complex, impairing mitochondrial energy metabolism $[10,60]$. Furthermore, the mitochondrial outer-membrane permeabilization induced by excessive ROS production promotes proapoptotic factor leakage and initiates caspase-9related mitochondrial apoptosis $[61,62]$. The hyperglycemiamediated glomerular death via mitochondrial apoptosis gradually leads to a reduction in functional cells in the kidneys,

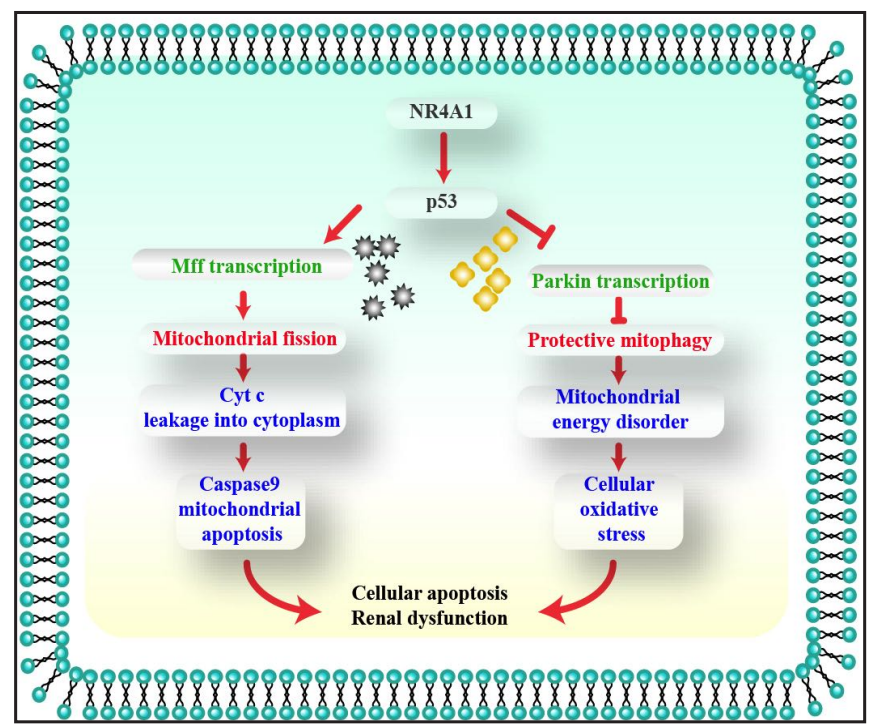

Fig. 8. NR4A1 upregulation induced by the hyperglycemiaactivated p53 pathways, stimulating Mff-mediated mitochondrial fission and inhibiting Parkin-mediated mitophagy. The imbalance in mitochondrial dynamics amplified glomerular apoptosis and worsened renal function. which unfortunately is repaired via collagen accumulation, progressively contributing to renal dysfunction [63, 64]. These data show the functional importance of mitochondrial damage in regulating the progression of diabetic nephropathy.

In the present study, we demonstrated that hyperglycemia-mediated mitochondrial damage can be attributed to mitochondrial fission activation and mitophagy inhibition. Excessive mitochondrial fission and mitophagy arrest produce numerous mitochondrial fragments, stimulating ROS overproduction, mPTP opening, cyt-c leakage, and caspase-9 activation $[17,18,31,65]$. We also identified NR4A1 as the regulator of hyperglycemiamediated fission augmentation and mitophagy delay because deletion of NR4A1 repressed the formation of mitochondrial fragmentation and promoted mitochondria fusion with lysosomes. In addition, we found that the genetic ablation of NR4A1 reversed the glucose metabolism parameter changes, decreased glomerular death and reduced diabetic renal fibrosis. Accordingly, our study highlights the fact that NR4A1-mediated fission activation and mitophagy inhibition are critical for diabetic renal injury and mitochondrial dysfunction.

Consistently with our findings, previous studies have reported that NR4A1 activation was noted in fatty liver disease and atherosclerosis [24, 25] and that the genetic deletion of NR4A1 or pharmacological inhibition of NR4A1 retards or prevents the progression of nonalcoholic fatty liver and atherosclerosis $[66,67]$. Collectively, these observations have demonstrated the sufficiency of NR4A1 to exacerbate chronic metabolic diseases, which may highlight a new method for treating chronic metabolic disorders by targeting NR4A1.

Although a mounting body of data has confirmed that fission activation and mitophagy inhibition are involved in diabetic renal damage via pleiotropic effects $[60,68]$, the upstream regulators of fission and mitophagy have not yet been fully elucidated. Previous studies have suggested that mitochondrial fission is highly governed by Drp1 translocation from the cytoplasm to mitochondria. However, Drp1's interaction with mitochondria requires its receptors, especially Mff $[11,17]$. We have illustrated that hyperglycemiamediated mitochondrial fission requires Mff, whose activity was enhanced by NR4A1 at the transcriptional level. Furthermore, impaired mitophagy resulted from downregulated Parkin, a regulator of mitophagy facilitating mitochondrial fusion with lysosomes. NR4A1 repressed Parkin transcription and therefore attenuated mitophagy activity. More importantly, our data 


\section{Cellular Physiology Cell Physiol Biochem 2018;48:1675-1693 and Biochemistry \begin{tabular}{l|l} 
DOI: 10.1159/000492292 \\
Published online: August 2, 2018 & $\begin{array}{l}\text { O 2018 The Author(s). Published by S. Karger AG, Basel } \\
\text { www.karger.com/cpb }\end{array}$ \\
\cline { 2 - 3 }
\end{tabular} \\ Sheng et al.: NR4A1 Regulates Diabetic Nephropathy}

revealed that $\mathrm{p} 53$ is required for NR4A1-regulated Mff/Parkin transcription. These results introduced the NR4A1-p53 signaling pathways as upstream regulators of hyperglycemiarelated fission and mitophagy.

Previous researchers have reported, similar to our reports, that NR4A1 could regulate mitochondrial fission and mitophagy at the same time in fatty liver disease [24, 69]. However, these authors argued that activated NR4A1 due to high-fat diets mediates Drp1 phosphorylation and represses Bnip3 transcription, leading to fission activation and mitophagy inhibition. Other signaling pathways may also be involved in simultaneously regulating fission and mitophagy $[70,71]$. In cardiac microvascular ischemia reperfusion, DUSP1 has been shown to repress fission and recuse mitophagy via the JNK pathway [17, 72]. In diabetic cardiomyopathy, AMPK is the upstream mediator of fission and mitophagy $[14,73]$. Further investigation of the roles of DUSP1 and the AMPK pathway in Mff-mediated fission and Parkin-mediated mitophagy is required for further insight into mitochondrial dynamics management in the setting of diabetic nephropathy.

In summary, our report highlights novel signal pathways controlling the progression of diabetic nephropathy via modulation of mitochondrial homeostasis: upregulated NR4A1 induced by hyperglycemia activated p53 pathways, stimulating Mff-mediated mitochondrial fission and inhibiting Parkin-mediated mitophagy. The imbalance in mitochondrial dynamics amplified glomerular apoptosis and impaired renal function. This result underlies the fact that fission and mitophagy are actually regulated by common upstream signals (the NR4A1-p53 signaling pathway) in the setting of hyperglycemic stress. In light of these findings, strategies to regulate the balance of the NR4A1-p53 signaling pathway and mitochondrial homeostasis may be a therapeutic target for treating diabetic nephropathy in clinical practice.

\section{Acknowledgements}

This study was financially supported by grants from the XuHui District medical peak subject construction project (SHXH201708) and the Xuhui District Central Hospital of Shanghai Initial Founding of Scientific Research for the Introduction of Talents (2017-2020). The funders had no role in the study design, data collection and analysis, decision to publish, or preparation of the manuscript.

\section{Disclosure Statement}

The authors declared that they have no conflicts of interest.

\section{References}

1 Yang S, Zhang J, Wang S, Shi J, Zhao X: Knockdown of Angiopoietin-Like Protein 2 Ameliorates Diabetic Nephropathy by Inhibiting TLR4. Cell Physiol Biochem 2017;43:685-696.

-2 Yang HH, Chen Y, Gao CY, Cui ZT, Yao JM: Protective Effects of MicroRNA-126 on Human Cardiac Microvascular Endothelial Cells Against Hypoxia/Reoxygenation-Induced Injury and Inflammatory Response by Activating PI3K/Akt/eNOS Signaling Pathway. Cell Physiol Biochem 2017;42:506-518.

3 Merjaneh M, Langlois A, Larochelle S, Cloutier CB, Ricard-Blum S, Moulin VJ: Pro-angiogenic capacities of microvesicles produced by skin wound myofibroblasts. Angiogenesis 2017;20:385-398.

4 Singh DK, Winocour P, Farrington K: Oxidative stress in early diabetic nephropathy: fueling the fire. Nat Rev Endocrinol 2011;7:176-184.

5 Garvin JL, Herrera M, Ortiz PA: Regulation of renal NaCl transport by nitric oxide, endothelin, and ATP: clinical implications. Annu Rev Physiol 2011;73:359-376.

6 Sharma K: Mitochondrial Dysfunction in the Diabetic Kidney. Adv Exp Med Biol 2017;982:553-562. 


\section{Cellular Physiology Cell Physiol Biochem 2018;48:1675-1693 \begin{tabular}{ll|l} 
and Biochemistry Published online: August 2, 2018 & $\begin{array}{l}\text { (c) } 2018 \text { The Author(s). Published by S. Karger AG, Basel } \\
\text { www.karger.com/cpb }\end{array}$
\end{tabular}}

7 Ren XS, Tong Y, Ling L, Chen D, Sun HJ, Zhou H, Qi XH, Chen Q, Li YH, Kang YM, Zhu GQ: NLRP3 Gene Deletion Attenuates Angiotensin II-Induced Phenotypic Transformation of Vascular Smooth Muscle Cells and Vascular Remodeling. Cell Physiol Biochem 2017;44:2269-2280.

8 Hallan S, Sharma K: The Role of Mitochondria in Diabetic Kidney Disease. Curr Diab Rep 2016;16:61.

-9 Lee HY, Back K: Melatonin is required for $\mathrm{H} 2 \mathrm{O} 2$ - and NO-mediated defense signaling through MAPKKK3 and OXI1 in Arabidopsis thaliana. J Pineal Res 2017;62:e12471.

10 Zhou H, Yue Y, Wang J, Ma Q Chen Y: Melatonin therapy for diabetic cardiomyopathy: A mechanism involving Syk-mitochondrial complex I-SERCA pathway. Cell Signal 2018;47:88-100.

-11 Zhou H, Hu S, Jin Q, Shi C, Zhang Y, Zhu P, Ma Q, Tian F, Chen Y: Mff-Dependent Mitochondrial Fission Contributes to the Pathogenesis of Cardiac Microvasculature Ischemia/Reperfusion Injury via Induction of mROS-Mediated Cardiolipin Oxidation and HK2/VDAC1 Disassociation-Involved mPTP Opening. J Am Heart Assoc 2017;6:e005328.

12 Ackermann M, Kim YO, Wagner WL, Schuppan D, Valenzuela CD, Mentzer SJ, Kreuz S, Stiller D, Wollin L, Konerding MA: Effects of nintedanib on the microvascular architecture in a lung fibrosis model. Angiogenesis 2017;20:359-372.

13 Zhou H, Shi C, Hu S, Zhu H, Ren J, Chen Y: BI1 is associated with microvascular protection in cardiac ischemia reperfusion injury via repressing Syk-Nox2-Drp1-mitochondrial fission pathways. Angiogenesis 2018;6:1-17.

14 Zhou H, Wang S, Zhu P, Hu S, Chen Y, Ren J: Empagliflozin rescues diabetic myocardial microvascular injury via AMPK-mediated inhibition of mitochondrial fission. Redox Biol 2018;15:335-346.

15 Wang W, Wang Y, Long J, Wang J, Haudek SB, Overbeek P, Chang BH, Schumacker PT, Danesh FR: Mitochondrial fission triggered by hyperglycemia is mediated by ROCK1 activation in podocytes and endothelial cells. Cell Metab 2012;15:186-200.

16 Gao Y, Xiao X, Zhang C, Yu W, Guo W, Zhang Z, Li Z, Feng X, Hao J, Zhang K, Xiao B, Chen M, Huang W, Xiong S, Wu X, Deng W: Melatonin synergizes the chemotherapeutic effect of 5-fluorouracil in colon cancer by suppressing PI3K/AKT and NF-kappaB/iNOS signaling pathways. J Pineal Res 2017;62:e12380.

17 Jin Q, Li R, Hu N, Xin T, Zhu P, Hu S, Ma S, Zhu H, Ren J, Zhou H: DUSP1 alleviates cardiac ischemia/ reperfusion injury by suppressing the Mff-required mitochondrial fission and Bnip3-related mitophagy via the JNK pathways. Redox Biol 2018;14:576-587.

18 Zhou H, Zhu P, Wang J, Zhu H, Ren J, Chen Y: Pathogenesis of cardiac ischemia reperfusion injury is associated with CK2alpha-disturbed mitochondrial homeostasis via suppression of FUNDC1-related mitophagy. Cell Death Differ 2018;25:1080-1093.

19 Zhou H, Zhang Y, Hu S, Shi C, Zhu P, Ma Q Jin Q, Cao F, Tian F, Chen Y: Melatonin protects cardiac microvasculature against ischemia/reperfusion injury via suppression of mitochondrial fission-VDAC1HK2-mPTP-mitophagy axis. J Pineal Res 2017;63:e12413.

20 Zhao Q, Ye M, Yang W, Wang M, Li M, Gu C, Zhao L, Zhang Z, Han W, Fan W, Meng Y: Effect of Mst1 on Endometriosis Apoptosis and Migration: Role of Drp1-Related Mitochondrial Fission and Parkin-Required Mitophagy. Cell Physiol Biochem 2018;45:1172-1190.

-21 Xiao L, Xu X, Zhang F, Wang M, Xu Y, Tang D, Wang J, Qin Y, Liu Y, Tang C, He L, Greka A, Zhou Z, Liu F, Dong Z, Sun L: The mitochondria-targeted antioxidant MitoQ ameliorated tubular injury mediated by mitophagy in diabetic kidney disease via Nrf2/PINK1. Redox Biol 2017;11:297-311.

-22 Randriamboavonjy V, Kyselova A, Elgheznawy A, Zukunft S, Wittig I, Fleming I: Calpain 1 cleaves and inactivates prostacyclin synthase in mesenteric arteries from diabetic mice. Basic Res Cardiol 2017;112:10.

23 Thirusangu P, Vigneshwaran V, Prashanth T, Vijay Avin BR, Malojirao VH, Rakesh H, Khanum SA, Mahmood R, Prabhakar BT: BP-1T, an antiangiogenic benzophenone-thiazole pharmacophore, counteracts HIF-1 signalling through p53/MDM2-mediated HIF-1alpha proteasomal degradation. Angiogenesis 2017;20:5571.

24 Zhou H, Du W, Li Y, Shi C, Hu N, Ma S, Wang W, Ren J: Effects of melatonin on fatty liver disease: The role of NR4A1/DNA-PKcs/p53 pathway, mitochondrial fission, and mitophagy. J Pineal Res 2018;64:e12450.

25 Zhu C, Shen H, Zhu L, Zhao F, Shu Y: Plasminogen Activator Inhibitor 1 Promotes Immunosuppression in Human Non-Small Cell Lung Cancers by Enhancing TGF-Beta1 Expression in Macrophage. Cell Physiol Biochem 2017;44:2201-2211. 


\section{Cellular Physiology Cell Physiol Biochem 2018;48:1675-1693 \begin{tabular}{ll|l} 
and Biochemistry Published online: August 2, 2018 & $\begin{array}{l}\text { (c) } 2018 \text { The Author(s). Published by S. Karger AG, Basel } \\
\text { www.karger.com/cpb }\end{array}$
\end{tabular}}

26 Feng J, Lu C, Dai Q Sheng J, Xu M: SIRT3 Facilitates Amniotic Fluid Stem Cells to Repair Diabetic Nephropathy Through Protecting Mitochondrial Homeostasis by Modulation of Mitophagy. Cell Physiol Biochem 2018;46:1508-1524.

27 Torres-Estay V, Carreno DV, Fuenzalida P, Watts A, San Francisco IF, Montecinos VP, Sotomayor PC, Ebos J, Smith GJ, Godoy AS: Androgens modulate male-derived endothelial cell homeostasis using androgen receptor-dependent and receptor-independent mechanisms. Angiogenesis 2017;20:25-38.

28 Shi C, Cai Y, Li Y, Li Y, Hu N, Ma S, Hu S, Zhu P, Wang W, Zhou H: Yap promotes hepatocellular carcinoma metastasis and mobilization via governing cofilin/F-actin/lamellipodium axis by regulation of JNK/Bnip3/ SERCA/CaMKII pathways. Redox Biol 2018;14:59-71.

-29 Nunez-Gomez E, Pericacho M, Ollauri-Ibanez C, Bernabeu C, Lopez-Novoa JM: The role of endoglin in postischemic revascularization. Angiogenesis 2017;20:1-24.

30 Yang G, Zhang X, Weng X, Liang P, Dai X, Zeng S, Xu H, Huan H, Fang M, Li Y, Xu D, Xu Y: SUV39H1 mediated SIRT1 trans-repression contributes to cardiac ischemia-reperfusion injury. Basic Res Cardiol 2017;112:22.

31 Zhou H, Zhu P, Guo J, Hu N, Wang S, Li D, Hu S, Ren J, Cao F, Chen Y: Ripk3 induces mitochondrial apoptosis via inhibition of FUNDC1 mitophagy in cardiac IR injury. Redox Biol 2017;13:498-507.

-32 Vargas LA, Velasquez FC, Alvarez BV: Compensatory role of the NBCn1 sodium/bicarbonate cotransporter on $\mathrm{Ca}(2+)$-induced mitochondrial swelling in hypertrophic hearts. Basic Res Cardiol 2017;112:14.

-33 Zhou H, Yang J, Xin T, Li D, Guo J, Hu S, Zhou S, Zhang T, Zhang Y, Han T, Chen Y: Exendin-4 protects adiposederived mesenchymal stem cells from apoptosis induced by hydrogen peroxide through the PI3K/AktSfrp2 pathways. Free Radic Biol Med 2014;77:363-375.

34 Zhang Y, Zhou H, Wu W, Shi C, Hu S, Yin T, Ma Q Han T, Zhang Y, Tian F, Chen Y: Liraglutide protects cardiac microvascular endothelial cells against hypoxia/reoxygenation injury through the suppression of the SR-Ca(2+)-XO-ROS axis via activation of the GLP-1R/PI3K/Akt/survivin pathways. Free Radic Biol Med 2016;95:278-292.

-35 Ligeza J, Marona P, Gach N, Lipert B, Miekus K, Wilk W, Jaszczynski J, Stelmach A, Loboda A, Dulak J, Branicki W, Rys J, Jura J: MCPIP1 contributes to clear cell renal cell carcinomas development. Angiogenesis 2017;20:325-340.

-36 Zhou H, Li D, Zhu P, Hu S, Hu N, Ma S, Zhang Y, Han T, Ren J, Cao F, Chen Y: Melatonin suppresses platelet activation and function against cardiac ischemia/reperfusion injury via PPARgamma/FUNDC1/mitophagy pathways. J Pineal Res 2017;63:e12438.

37 Wang K, Gan TY, Li N, Liu CY, Zhou LY, Gao JN, Chen C, Yan KW, Ponnusamy M, Zhang YH, Li PF: Circular RNA mediates cardiomyocyte death via miRNA-dependent upregulation of MTP18 expression. Cell Death Differ 2017;24:1111-1120.

-38 Hu SY, Zhang Y, Zhu PJ, Zhou H, Chen YD: Liraglutide directly protects cardiomyocytes against reperfusion injury possibly via modulation of intracellular calcium homeostasis. J Geriatr Cardiol 2017;14:57-66.

-39 Garcia-Nino WR, Correa F, Rodriguez-Barrena JI, Leon-Contreras JC, Buelna-Chontal M, Soria-Castro E, Hernandez-Pando R, Pedraza-Chaverri J, Zazueta C: Cardioprotective kinase signaling to subsarcolemmal and interfibrillar mitochondria is mediated by caveolar structures. Basic Res Cardiol 2017;112:15.

-40 Brasacchio D, Alsop AE, Noori T, Lufti M, Iyer S, Simpson KJ, Bird PI, Kluck RM, Johnstone RW, Trapani JA: Epigenetic control of mitochondrial cell death through PACS1-mediated regulation of BAX/BAK oligomerization. Cell Death Differ 2017;24:961-970.

-41 Rossello X, Riquelme JA, He Z, Taferner S, Vanhaesebroeck B, Davidson SM, Yellon DM: The role of PI3Kalpha isoform in cardioprotection. Basic Res Cardiol 2017;112:66.

-42 Schock SN, Chandra NV, Sun Y, Irie T, Kitagawa Y, Gotoh B, Coscoy L, Winoto A: Induction of necroptotic cell death by viral activation of the RIG-I or STING pathway. Cell Death Differ 2017;24:615-625.

43 Zhou H, Wang J, Zhu P, Zhu H, Toan S, Hu S, Ren J, Chen Y: NR4A1 aggravates the cardiac microvascular ischemia reperfusion injury through suppressing FUNDC1-mediated mitophagy and promoting Mffrequired mitochondrial fission by CK2alpha. Basic Res Cardiol 2018;113:23.

44 Zhou H, Li D, Zhu P, Ma Q, Sam T, Wang J, Hu S, Chen Y, Zhang Y: Inhibitory effect of melatonin on necroptosis via repressing the Ripk3-PGAM5-CypD-mPTP pathway attenuates cardiac microvascular ischemia reperfusion injury. J Pineal Res 2018;65:e12503.

45 Banerjee K, Keasey MP, Razskazovskiy V, Visavadiya NP, Jia C, Hagg T: Reduced FAK-STAT3 signaling contributes to ER stress-induced mitochondrial dysfunction and death in endothelial cells. Cell Signal 2017;36:154-162. 


\section{Cellular Physiology Cell Physiol Biochem 2018;48:1675-1693 \begin{tabular}{ll|l} 
and Biochemistry Published online: August 2, 2018 & $\begin{array}{l}\text { (c) } 2018 \text { The Author(s). Published by S. Karger AG, Basel } \\
\text { www.karger.com/cpb }\end{array}$
\end{tabular}}

46 Das N, Mandala A, Naaz S, Giri S, Jain M, Bandyopadhyay D, Reiter RJ, Roy SS: Melatonin protects against lipid-induced mitochondrial dysfunction in hepatocytes and inhibits stellate cell activation during hepatic fibrosis in mice. J Pineal Res 2017;62:e12404

47 Daiber A, Oelze M, Steven S, Kroller-Schon S, Munzel T: Taking up the cudgels for the traditional reactive oxygen and nitrogen species detection assays and their use in the cardiovascular system. Redox Biol 2017;12:35-49.

48 Dufour F, Rattier T, Shirley S, Picarda G, Constantinescu AA, Morle A, Zakaria AB, Marcion G, Causse S, Szegezdi E, Zajonc DM, Seigneuric R, Guichard G, Gharbi T, Picaud F, Herlem G, Garrido C, Schneider P, Benedict CA, Micheau 0: N-glycosylation of mouse TRAIL-R and human TRAIL-R1 enhances TRAIL-induced death. Cell Death Differ 2017;24:500-510.

49 Alghanem AF, Wilkinson EL, Emmett MS, Aljasir MA, Holmes K, Rothermel BA, Simms VA, Heath VL, Cross MJ: RCAN1.4 regulates VEGFR-2 internalisation, cell polarity and migration in human microvascular endothelial cells. Angiogenesis 2017;20:341-358.

50 Jovancevic N, Dendorfer A, Matzkies M, Kovarova M, Heckmann JC, Osterloh M, Boehm M, Weber L, Nguemo F, Semmler J, Hescheler J, Milting H, Schleicher E, Gelis L, Hatt H: Medium-chain fatty acids modulate myocardial function via a cardiac odorant receptor. Basic Res Cardiol 2017;112:13.

51 Oanh NTK, Park YY, Cho H: Mitochondria elongation is mediated through SIRT1-mediated MFN1 stabilization. Cell Signal 2017;38:67-75.

52 Lee K, Back K: Overexpression of rice serotonin N-acetyltransferase 1 in transgenic rice plants confers resistance to cadmium and senescence and increases grain yield. J Pineal Res 2017;62:e12392.

-53 Rienks M, Carai P, Bitsch N, Schellings M, Vanhaverbeke M, Verjans J, Cuijpers I, Heymans S, Papageorgiou A: Sema3A promotes the resolution of cardiac inflammation after myocardial infarction. Basic Res Cardiol 2017;112:42.

-54 Laakkonen JP, Lappalainen JP, Theelen TL, Toivanen PI, Nieminen T, Jauhiainen S, Kaikkonen MU, Sluimer JC, Yla-Herttuala S: Differential regulation of angiogenic cellular processes and claudin- 5 by histamine and VEGF via PI3K-signaling, transcription factor SNAI2 and interleukin-8. Angiogenesis 2017;20:109-124.

55 Le Cras TD, Mobberley-Schuman PS, Broering M, Fei L, Trenor CC, 3rd, Adams DM: Angiopoietins as serum biomarkers for lymphatic anomalies. Angiogenesis 2017;20:163-173.

56 Van Nostrand JL, Bowen ME, Vogel H, Barna M, Attardi LD: The p53 family members have distinct roles during mammalian embryonic development. Cell Death Differ 2017;24:575-579.

57 Hu Z, Cheng J, Xu J, Ruf W, Lockwood CJ: Tissue factor is an angiogenic-specific receptor for factor VIItargeted immunotherapy and photodynamic therapy. Angiogenesis 2017;20:85-96.

58 Kingery JR, Hamid T, Lewis RK, Ismahil MA, Bansal SS, Rokosh G, Townes TM, Ildstad ST, Jones SP, Prabhu SD: Leukocyte iNOS is required for inflammation and pathological remodeling in ischemic heart failure. Basic Res Cardiol 2017;112:19.

\$9 Murphy PS, Wang J, Bhagwat SP, Munger JC, Janssen WJ, Wright TW, Elliott MR: CD73 regulates antiinflammatory signaling between apoptotic cells and endotoxin-conditioned tissue macrophages. Cell Death Differ 2017;24:559-570.

-60 Sarkar C, Ganju RK, Pompili VJ, Chakroborty D: Enhanced peripheral dopamine impairs post-ischemic healing by suppressing angiotensin receptor type 1 expression in endothelial cells and inhibiting angiogenesis. Angiogenesis 2017;20:97-107.

-61 Ni Z, Tao L, Xiaohui X, Zelin Z, Jiangang L, Zhao S, Weikang H, Hongchao X, Qiujing W, Xin L: Polydatin impairs mitochondria fitness and ameliorates podocyte injury by suppressing Drp1 expression. J Cell Physiol 2017;232:2776-2787.

62 Yu S, Wang X, Geng P, Tang X, Xiang L, Lu X, Li J, Ruan Z, Chen J, Xie G, Wang Z, Ou J, Peng Y, Luo X, Zhang X, Dong Y, Pang X, Miao H, Chen H, Liang H: Melatonin regulates PARP1 to control the senescence-associated secretory phenotype (SASP) in human fetal lung fibroblast cells. J Pineal Res 2017;63:e12405.

63 Qi H, Casalena G, Shi S, Yu L, Ebefors K, Sun Y, Zhang W, D’Agati V, Schlondorff D, Haraldsson B, Bottinger E, Daehn I: Glomerular Endothelial Mitochondrial Dysfunction Is Essential and Characteristic of Diabetic Kidney Disease Susceptibility. Diabetes 2017;66:763-778.

-64 Garcia-Ruiz JM, Galan-Arriola C, Fernandez-Jimenez R, Aguero J, Sanchez-Gonzalez J, Garcia-Alvarez A, Nuno-Ayala M, Dube GP, Zafirelis Z, Lopez-Martin GJ, Bernal JA, Lara-Pezzi E, Fuster V, Ibanez B: Bloodless reperfusion with the oxygen carrier HBOC-201 in acute myocardial infarction: a novel platform for cardioprotective probes delivery. Basic Res Cardiol 2017;112:17. 


\section{Cellular Physiology Cell Physiol Biochem 2018;48:1675-1693 \begin{tabular}{l|l} 
DOI: 10.1159/000492292 & and Biochemistry \\
Published online: August 2, 2018 & $\begin{array}{l}\text { 2 2018 The Author(s). Published by S. Karger AG, Basel } \\
\text { www.karger.com/cpb }\end{array}$ \\
\cline { 2 - 3 }
\end{tabular} \\ Sheng et al.: NR4A1 Regulates Diabetic Nephropathy}

65 Zhou H, Wang J, Zhu P, Hu S, Ren J: Ripk3 regulates cardiac microvascular reperfusion injury: The role of IP3R-dependent calcium overload, XO-mediated oxidative stress and F-action/filopodia-based cellular migration. Cell Signal 2018;45:12-22.

66 Couto JA, Ayturk UM, Konczyk DJ, Goss JA, Huang AY, Hann S, Reeve JL, Liang MG, Bischoff J, Warman ML, Greene AK: A somatic GNA11 mutation is associated with extremity capillary malformation and overgrowth. Angiogenesis 2017;20:303-306.

67 Chang SH, Yeh YH, Lee JL, Hsu YJ, Kuo CT, Chen WJ: Transforming growth factor-beta-mediated CD44/ STAT3 signaling contributes to the development of atrial fibrosis and fibrillation. Basic Res Cardiol 2017;112:58.

68 Zhao Y, Guo Y, Jiang Y, Zhu X, Liu Y, Zhang X: Mitophagy regulates macrophage phenotype in diabetic nephropathy rats. Biochem Biophys Res Commun 2017;494:42-50.

69 Lassen TR, Nielsen JM, Johnsen J, Ringgaard S, Botker HE, Kristiansen SB: Effect of paroxetine on left ventricular remodeling in an in vivo rat model of myocardial infarction. Basic Res Cardiol 2017;112:26.

70 Wang N, Liu H, Li X, Zhang Q, Chen M, Jin Y, Deng X: Activities of MSCs Derived from Transgenic Mice Seeded on ADM Scaffolds in Wound Healing and Assessment by Advanced Optical Techniques. Cell Physiol Biochem 2017;42:623-639.

71 Iggena D, Winter Y, Steiner B: Melatonin restores hippocampal neural precursor cell proliferation and prevents cognitive deficits induced by jet lag simulation in adult mice. J Pineal Res 2017;62:e12397.

72 Tamura H, Kawamoto M, Sato S, Tamura I, Maekawa R, Taketani T, Aasada H, Takaki E, Nakai A, Reiter RJ, Sugino N: Long-term melatonin treatment delays ovarian aging. J Pineal Res 2017;62:e12381.

73 Kang PT, Chen CL, Lin P, Chilian WM, Chen YR: Impairment of pH gradient and membrane potential mediates redox dysfunction in the mitochondria of the post-ischemic heart. Basic Res Cardiol 2017;112:36. 